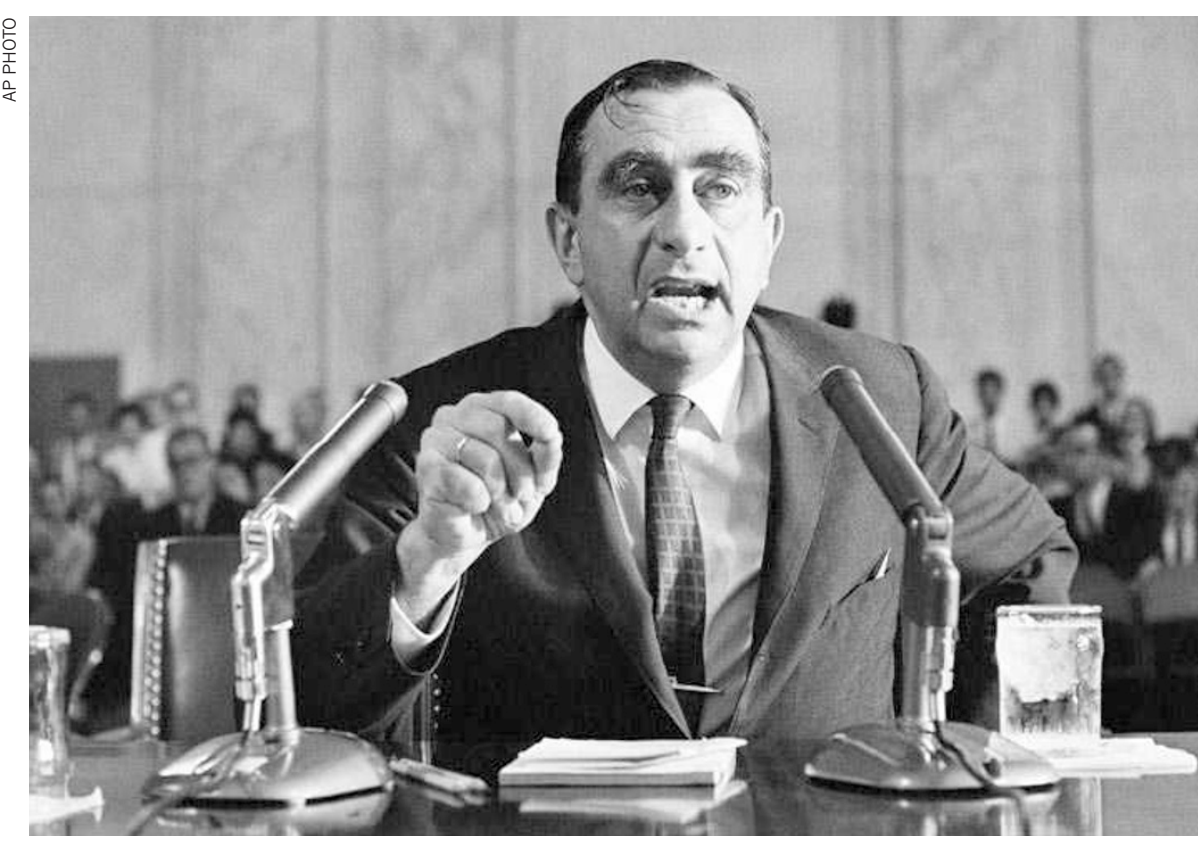

Physicist Edward Teller insisted on building the hydrogen bomb, and opposed nuclear test-ban treaties. BIOGRAPHY

\title{
Envy and power
}

\section{A balanced biography brings out the many contradictions of nuclear physicist Edward Teller, finds Robert P. Crease.}

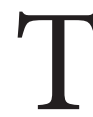

The Hungarian-born US physicist Edward Teller (1908-2003) is remembered less for his scientific achievements than for his political crusades. These include spearheading the development of the hydrogen bomb, demolishing the influence of atomic physicist J. Robert Oppenheimer in government circles, opposing nuclear test-ban treaties, and championing the flawed US Strategic Defense Initiative.

Although Teller's motivations were patriotic, he left turmoil and bitterness in his wake. Judging Edward Teller provides a much needed, complex personal portrait of an influential scientist, even if it does not set him fully on the world stage.

Teller saw the world in black and white. He evokes a similarly polarized reaction, making it difficult to evaluate his legacy fairly. Biographer and chemist István Hargittai has an advantage in coming from a Jewish Hungarian background similar to that of his subject. Hargittai notes that he aimed "to be appreciative of [Teller's] virtues and to be conscious of his flaws". Teller had both in abundance.

Teller's early life was dramatic. He spent his first 18 years in Hungary during a tumultuous era that included the 'happy peacetime' of the Austro-Hungarian monarchy, the devastation of the First World War, the country's humiliating dismemberment, democracy, communism, rightwing terror and antiSemitism. In 1920 , Hungary enacted a law called numerus clausus ('closed number'), which restricted the number of Jewish students allowed in higher education. This law, Hargittai says, had the "dubious distinction of being the first anti-Jewish legislation after World War I in Europe".

Hargittai describes

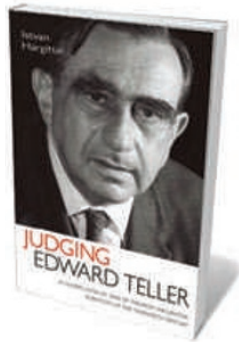

Judging Edward Teller: A Closer Look at One of the Most Influential Scientists of the Twentieth Century ISTVÁN HARGITTAI Prometheus Books: 2010.575 pp. \$32, $£ 29.95$

Teller's adult life as a series of three exiles. The first began in 1926, when he left Hungary for Germany. Calling this an exile seems forced, however Teller's outstanding academic performance exempted him from the numerus clausus. Furthermore, his departure was anticipated: his family, like those of many other Hungarian Jews, prepared their children linguistically and culturally for emigration to Germany, where the culture was livelier and where educational and job prospects were superior.

Teller was fortunate: Germany was a scientific superpower and German was seen as the "language of science". He studied chemical engineering in Karlsruhe, physics in Munich, received $\mathrm{ahD}$ in physics under Werner Heisenberg in 1930 at Leipzig, and from 1931-3 worked in Göttingen with physical chemist Arnold Eucken. While in Munich in 1928, a tram wheel severed his right foot and he wore a prosthesis for the rest of his life. This left him determined to overcome adversity, and with the need to carry a trademark cane that he would pound on the floor for emphasis when speaking.

Soon after the Nazis assumed power in 1933, Teller fled Germany. This was a genuine exile: sudden and with no clear destination, thrusting him into unfamiliar territory. Aided by a British programme to rescue Jewish scientists, Teller spent time in Copenhagen and London, and moved to the United States in 1935. When the Second World War broke out, his friendship with fellow Hungarian physicist Leo Szilard got him a position on the US atomic bomb project. He quickly went from being a ringside viewer to an active participant of the theoretical group at the Los Alamos laboratory in New Mexico. Teller could be exuberant and generous, but also envious and self-important. At Los Alamos, these negative traits began to disrupt relationships with colleagues, leading him to bear grudges against lab director Oppenheimer and others.

After the war, Teller pursued a series of causes that prompted nuclear physicist Enrico Fermi to label him "a monomaniac with many manias". One was Teller's insistence on developing, and getting credit for, the hydrogen bomb. Hargittai diligently traces Teller's changing stories of the bomb's history, describing at least five versions Teller gave with different names, dates and deeds. Hargittai quips that if the changes were plotted as a graph, they would show that "what should have been a fairly constant set of attributes appear to be fast-moving variables".

In April 1954, Teller testified against Oppenheimer at a hearing convened by the US Atomic Energy Commission in Washington DC, which considered Oppenheimer's appeal of the revocation of the security clearance needed for him to continue to be an adviser on atomic policy. Teller stated: "I would prefer to see the vital interests of this country in hands that I understand better and therefore trust more." In his autobiography Memoirs (Perseus Books, 2001) and else-
ЭNATURE.COM For a review of an Oppenheimer biography, see: go.nature.com/16m7nw where, Teller said that he had planned to testify that Oppenheimer should be cleared, but changed his mind after seeing parts 
of Oppenheimer's trial testimony. This recollection has been shown by historians to be incorrect: Teller had already significantly contributed to the anti-Oppenheimer case.

Teller's testimony was not the decisive point of the hearing - the inevitable outcome of which was to deny Oppenheimer's appeal and thus exclude him from government circles - but it was the psychological coup de grâce. Those who knew Oppenheimer found Teller's remarks preposterous. From then on, many refused to acknowledge him, isolating him from the mainstream physics community. Thus began what Hargittai calls Teller's third exile; again, a description that is a stretch, because it was self-inflicted and because Teller blossomed into an influential and canny insider in US political and military circles. "Edward understood power," remarked George Keyworth, science adviser to President Ronald Reagan. "He could have written [Machiavelli's] The Prince."

Hargittai is an acute observer of Teller's personal interactions. He gives an astute reading, for instance, of Teller's letters to the German-American physicist Maria Goeppert Mayer, which ranged from physics to personal matters. Hargittai exposes Teller's half-truths and falsehoods, including his erroneous suggestion that he opposed dropping the atomic bomb on Hiroshima. Such revisionist statements might be described as 'truthy' in the sense applied by US comedian Stephen Colbert to the remarks of certain politicians - as portraying the truth they want to exist. Hargittai also points out exaggerations by Teller's critics, such as unjustified comparisons with Trofim Lysenko, the biologist who destroyed Soviet genetics by sending it on a politically thrilling but scientifically questionable crusade.

Hargittai sometimes acts too much like an umpire, evaluating claims about Teller rather than appraising him as a moral and political agent. It would have been intriguing to investigate the psychological factors at work in a person whose idea of protecting his adopted country was to damage its science base by undermining eminent people whose views were less extreme than his own. How did such an envious and petulant individual become a point person for the US military? Answering such issues would require more background knowledge than Hargittai provides about the US weapons establishment, which itself used Teller as much as he used it. It would also require an understanding of the pernicious US preoccupation with security that often moves its leaders to damage their country in order to save it.

Robert P. Crease is professor of philosophy at Stony Brook University, New York 11794, USA, and author of The Great Equations. e-mail:rcrease@notes.cc.sunysb.edu

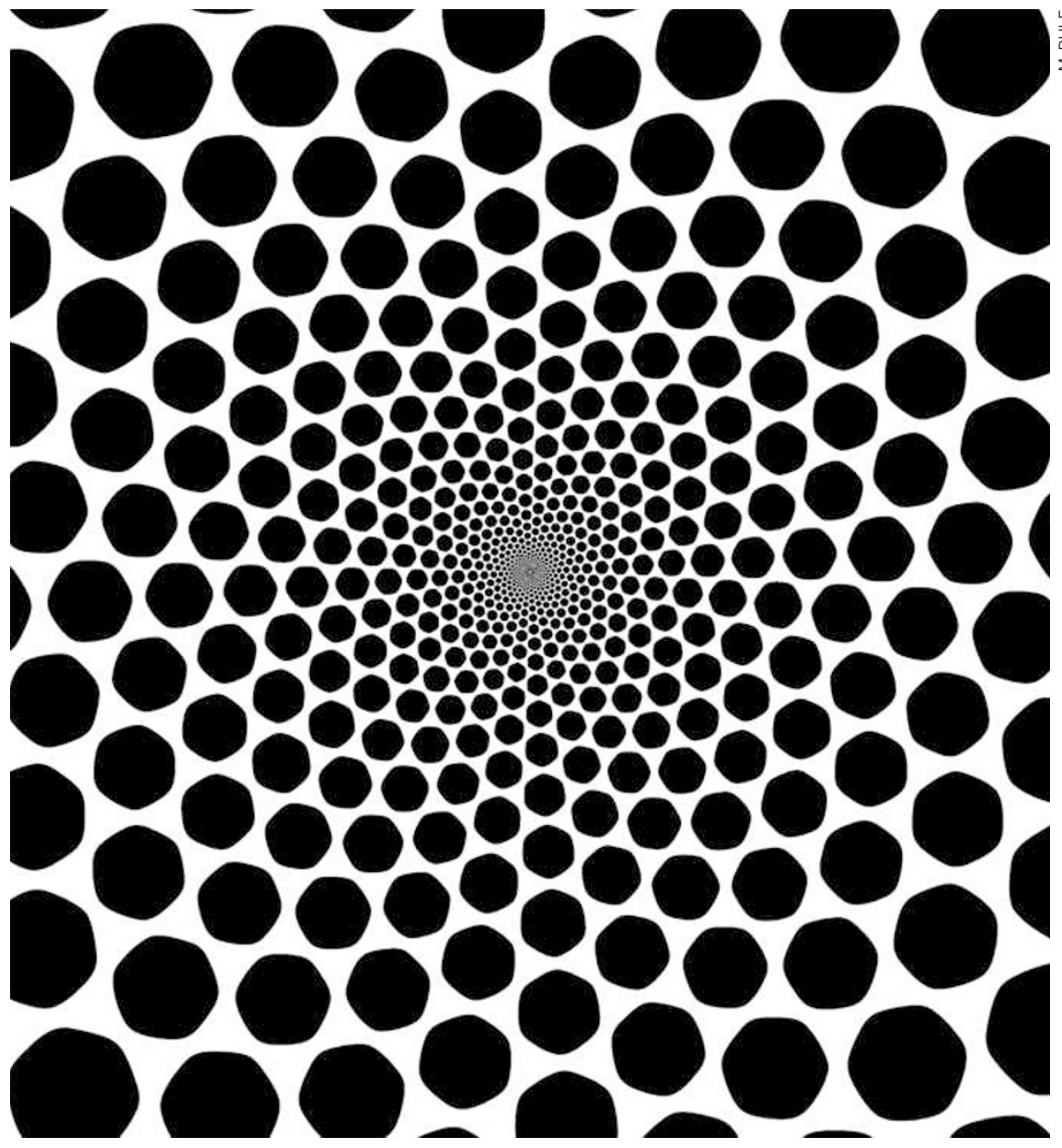

The visual disturbances seen by some people with migraines can be modelled mathematically.

\section{NEUROSCIENCE}

\section{Patterns from the brain}

\section{Vincent A. Billock recommends an introduction to the mathematics of geometric hallucinations.}

U ntil recently, biologists treated theory as a reward, claimed after a lifetime of labour in experiment and observation. Yet, within just a few generations, theorists in neuroscience have begun to resemble their cousins in physics, choosing to specialize in theory early in their careers. The focus of theoretical neuroscience has shifted in that time towards complexity: from models of nerve conduction to an emphasis on the dynamics of nonlinear neural interactions. Bard Ermentrout, a biophysicist, had much to do with that transformation, which is highlighted in his and mathematician David Terman's textbook, Mathematical Foundations of Neuroscience.

Terman and Ermentrout share an interest in the failure modes of neural systems. Nonlinear dynamic aspects are often only revealed when neural systems are pushed to the edges of their performance abilities. Migraines, strobe lights and drug intoxication can all cause geometric hallucinations: Ermentrout studies these as well as the illusions produced by viewing moving images during electric reti-

"Should maths
be conveyed
separately
to students
who show
theoretical
aptitude, or
mixed in as
digressions
to a lecture
series?"
nal stimulation. Terman's model of image segmentation fragments noisy images (such as television static) in a manner that is reminiscent of these visual effects. However, aside from geometric hallucinations, the wilder 